Journal of Engineering and Applied Sciences 14 (Special Issue 9): 10544-10548, 2019

ISSN: 1816-949X

(C) Medwell Journals, 2019

\title{
Social Network Sites in Travel and Tourism: Benefits and Limitations
}

\author{
Jaroslav Kacetl and Blanka Klimova \\ Faculty of Informatics and management, University of Hradec Kralove, \\ Rokitanskeho 62, 50003 Hradec Kralove, Czech Republic
}

\begin{abstract}
The purpose of this study is to explore the most frequently used Social Network Sites (SNSs) in travel and tourism as well as to discuss and summarize their benefits and limitations for the travel and tourism industry. It is particularly useful for the author's students of Management of Travel and Tourism at the Faculty of Informatics and Management, University of Hradec Kralove who will need the knowledge of SNSs as a prerequisite for being successful in their future profession. First, this study uses the method of literature review which is applied to determine the most popular SNSs in travel and tourism. Then, thus selected SNSs are compared and evaluated. There is a number of SNSs used for the travel and tourism purposes. However, the most popular SNSs are still Facebook and Twitter. As the findings show, the SNSs used for the travel and tourism purposes provide their users with travel information and/or facilitate contacts. Among the benefits belong an easy access to various content. Limitations include lower control over this content.
\end{abstract}

Key words: Social network sites, travel and tourism, benefits, limitations, various, knowledge

\section{INTRODUCTION}

Social Network Sites (SNSs) are becoming an inseparable part of people's everyday activities, both for business and private purposes. There are now many definitions of SNSs. One of the most cited is provided by Boyd and Ellison (2007) who define social network sites as follows: SNSs are web-based services that allow individuals to construct a public or semi-public profile within a bounded system; articulate a list of other users with whom they share a connection and view and traverse their list of connections and those by other within the system. They also put the main emphasis on their social aspect since these social network sites enable users to articulate and make visible their social networks (Poulova and Klimova, 2015).

SNSs are now on their rise. The most popular social network site is undoubtedly Facebook, followed by Twitter. Since, SNSs penetrate in all human activities, they also play a considerable role in travel and tourism business which is closely connected with the new information and communication technologies. In fact, Werthner and Ricci (2004) claim that travel and tourism industry is at the head of the Internet use and online transactions. In travel and tourism industry SNSs are part of other social media platforms such as blogs, forums, wikis, video and photo sharing, virtual communities, chat rooms and podcasts (UMOSM., 2008).

For example, Lange and Elliot (2012) state that travellers use SNSs in order to plan their trips and holidays. SNSs are important in their information search about the place, its attractiveness or accommodation possibilities. All this information is influenced by age, gender, culture and other demographic and sociographic features. In addition, travel and tourism industry is based on the use of word-of-mouth recommendations and SNSs such as Facebook or Twitter enable their users to share their travel experiences. As Nielsen (2013) presents, 84\% of consumers trust these recommendations. Furthermore, Bennett (2012) states that $64 \%$ of non-US travellers use social networks while travelling, $85 \%$ of leisure travellers use their smartphone abroad and 30\% of them have already used mobile applications to find hotel deals. In addition, 52\% of Facebook users have been inspired in their holiday planning by their friend's photos or $76 \%$ of travellers have posted their holiday photos to a social network site. Overall, SNSs enable travellers to have more control over their travel decision making process (Cox et al., 2007).

Therefore, the purpose of this study is to explore those social network sites that are most frequently used in travel and tourism and discuss and summarize their benefits and limitations for the travel and tourism industry (SD., 2016).

\section{MATERIALS AND METHODS}

Firstly, a method of literature search of available sources exploring the issue of social network sites in the field of travel and tourism was applied. A search was conducted in the world's acknowledged databases such as Web of Science, Scopus, Springer and ScienceDirect. Furthermore, other sources cited in the analysed studies were also examined. Secondly, on the basis of evaluation 


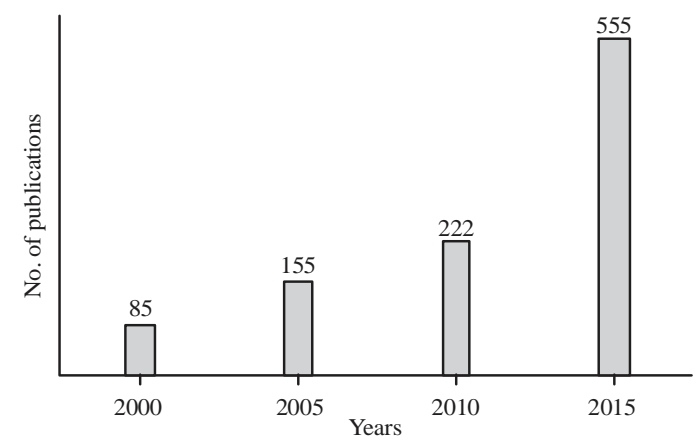

Fig. 1: A number of publications on SNSs in travel and tourism (researchers own processing, based on the data from (SD., 2016)

of these literature sources, the researched issue was explored. The research studies were classified according to their relevancy.

Although, there are not many research studies on the issue of SNSs in travel and tourism, there is a noticeable increase in the number of these publications (Fig. 1).

Social network sites and their use in tourism: The existence of SNS is enabled by the fact that ordinary people could start to use the Internet and it has become the mainstream and therefore, truly social. It coincides with Web 2.0, the second generation of web-based services which enables large-scale sharing. According to PRC. (2016), the SNS take-off point can be identified between February, 2005 and August, 2006. It was important that the Internet has enabled anyone not only to access information but also to communicate with other people, become a member of online communities and to create and share content of various kinds. Web 2.0 is not only social and extremely dynamic but also hard to understand. As Ali and Frew (2013) maintain, it is impossible to make an exact taxonomy of Web 2.0 tools and applications.

According to the website Tourism (2016), there are a few monitoring services specializing in social media like Hootsuite (2016) which enables its customers to manage up to a hundred social networks or SS. (2016). These monitoring services can gather messages for their customers, usually businesses, from multiple channels in one place and thus enable these businesses to communicate freely with their customers, understand the customer's feelings about the brand and instantly react if necessary to any negative trends among any particular group of customers. These services can also monitor conversations happening elsewhere on the Internet including blogs, forums and other public sites, social networks and platforms.

Most SNSs are used by both individuals and businesses in order to network and then stay in touch with other people and/or customers and to gather a wide variety of information about them. SNS usually allow their users to exchange messages both publicly and privately, form groups, create public pages as well as events, share and tag photographs, audio and video and much more. According to PRC. (2016) as of January 2014, 74\% of online adult Americans use social networking sites whereas as of February 2005 it was only 9\% of all American internet users. The same source (PRC., 2016) provides information on most popular SNSs among Americans as of September 2014:

- $\quad$ About $71 \%$ of online adults use Facebook

- About $23 \%$ of online adults use Twitter

- $\quad$ About 26\% use Instagram

- $\quad$ About 28\% use Pinterest

- $\quad$ About 28\% use LinkedIn

Ali and Frew (2013) made a list of most popular Web 2.0 sites, topped by Facebook and YouTube (Anonymous, 2013), both with 800 million users, followed by Qzone (480 million), Twitter (300 million), Renden (160 million), LinkedIn (120 million), Vkontakte, currently called VK (111 million) and others. The same list (Ali and Frew, 2013) also features several sites aiming at travel and tourism-WAYN (travel and lifestyle, 10 million), Couchsurfing (traveller-community interaction site, 2.9 million), Travelbuddy (linking travel, 1.6 million), Travellerspoint (travel community blogsite, 0.3 million). All of the most popular SNSs contain information that may be exploited in travel and tourism-Facebook as well as other top sites like Twitter or LinkedIn are full of travel-related ads and help all kinds of travellers to find what they are looking for.

Of course, the above mentioned most popular SNSs may be used for promoting travel and tourism. However, they do not focus on travel and tourism like some other sites. One of the rankings of the best SNSs in the field of travel and tourism (Anonymous, 2013) features at the top two general SNSs (Facebook and Twitter) which are followed by WAYN, Airbnb.com and TripAdvisor. Ali and Frew (2013) list among the most popular travelrelated SNSs WAYN, Couchsurfing, Travelbuddy and Travellerspoint. Figure 2 illustrates the five best network sites used in travel and tourism.

WAYN was initially an entirely travel-related SNS connecting people who happened to be in the same location. Later, however, it widened its scope to dating and other activities. Its users create their profile and upload photographs. WAYN users can ask for travel recommendations by posting questions to other users. WAYN also helps its users plan their trips. If one looks for a destination, WAYN provides relevant information about accommodation, best photos, top questions and answers, travellers tips, tours and attractions and much more. Alternatively, one can look for top destinations for 


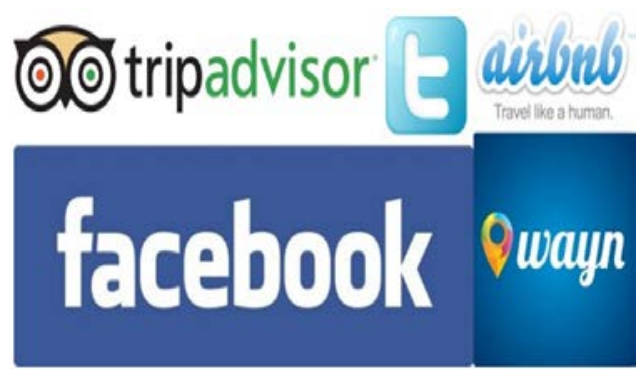

Fig. 2: Five best social network sites used in travel and tourism (Anonymous, 2013)

various kinds of activities or attractions such as hiking, cycling, beautiful architecture or beautiful scenery, based on WAYN user's votes. WAYN users may view their destination list or share with other users memories of a place they all visited in the Who's Around section. It is also possible to add images to one's destinations. Last but not least, WAYN's members and experts also determine Top Places in several categories.

Airbnb.com originally offered short-term living quarters, breakfast and a unique business networking opportunity (Anonymous, 2013). Airbnb is still mainly for those who are looking for accommodation in various places around the world. In order to become a user, one must sign up and create their own personal profile. The Airbnb official website says Airbnb host network covers 190 countries and 34,000 cities. Its users may check photos of offered accommodation, host profiles and reviews. Airbnb users can narrow their search according to the type of accommodation, its price and location. The site makes it easy to contact hosts and book one's stay.

TA. (2016) is rather a travel website than an SNS (Anonymous, 2013). It enables anybody to book hotels, flights and vacation rentals, to find restaurants and thingsto-do in one's destination. It updates travellers about the weather forecast for particular destinations, offers forums, reviews, traveller articles, travel guides, it also shows maps, calls the traveller's attention to most popular places, traveller photographs and much more.

Couchsurfing seems to be very similar to Airbnb as it is a service that connects its members who sign in and complete their profiles featuring their home base, lifestyle, mission and what they consider important. Couchsurfing members make up a global community of travellers who share their homes with other couchsurfers. They can also create local communities by means of Place Page. Locally, they hold and attend more or less regular events. Globally, they choose places to visit and look for potential hosts there by sending Couchrequests. Members may become hosts themselves.

Travelbuddy is a website whose users look for people to travel with. It is possible to set specific search criteria, like sex and age of a potential travel buddy, destinations one wants to visit and travel dates.
Travellerspoint is another travel community website. It offers highlights where anybody can create their own travel blog or find advice on trip preparation. There is also a forum for those who want to ask or inform others about virtually anything. Users can join various groups or upload travel photographs. It is possible to look there for accommodation tips, users can create maps of their travels and use a travel planner. The website also features travel guides for various regions, sub-regions, countries and territories.

All in all, travel and tourism can be promoted by means of both general and travel-and-tourism-orientated SNSs. The general ones usually contain travel ads. Companies active in travel and tourism have their fan sites there. SNSs promoting travel and tourism can be divided into two categories. The likes of WAYN, TripAdvisor, Travellerspoint provide their users with information about destinations and enable them to exchange their experience and knowledge about places, attractions and activities. SNSs like Airbnb.com, Couchsurfing or Travelbuddy focus on facilitating contacts among people as they put together those who look for and provide accommodation and/or company on trips.

\section{RESULTS AND DISCUSSION}

Discussion of the findings: As the findings show, there is an increasing number of successful SNSs used for the travel and tourism purposes. However, the most popular SNSs are still Facebook and Twitter. A case study by Buted et al. (2014) also shows that the most popular SNSs for tourism industry in Batangas province, Philippines are Facebook, Twitter and YouTube which serve as good tools for the dissemination of information very fast and at low costs. On the contrary, the negative aspect is that traveller's opinions are not well presented which leads to bad impressions and unfair criticism.

In addition, online communities have a strong impact on traveller's decisions and on the overall image and marketing of a particular destination. As Kiralova and Pavliceka (2015) state, social network sites can help destinations to remain competitive if they present attractive content, exploit creativity and support and stimulate interactive communication. However, to have an influence on traveller's decisions, they must be excellent in a sense of resembling the most glossy and popular magazines. Moreover, they should address travellers as individuals, i.e., they should be personalized. But they should also be dynamic and interactive and provide travellers with s unique experience (Morrison, 2013).

Karnstedt et al. (2011) list seven benefits SNSs might have for travel and tourism destination organizations which include: solicit endorsements; maximize revenue per seat; bond with guests; manage reputation; reach out 
Table 1: Benefits and limitations of SNSs for travel and tourism industry Benefits Limitations

They are able to address a big number of global travellers at relatively low costs and higher level of efficiency They enable to build and maintain a community of interest

They enable twenty four hours operations regardless different time zones

They enable to post and present traveller's current photos, videos, opinions, experience or experiences They are valuable source of word-of-mouth recommendations They help to build brand equity

They provide feedback for

destination management

organizations

They enable businesses to instantly react to emerging trends

Researchers own processing

to new customers; recruit new staff and build a buzz. Table 1 then summarizes the main benefits and limitations of SNSs for travel and tourism industry.

\section{CONCLUSION}

Currently, social network sites have a tremendous influence on how tourists create organise and share tourism experiences (Rathonyi, 2013). And since tourism is the main source of revenue in many countries and regions, tourist destination organizations should bear this fact on their mind and take a challenge to promote their places via SNSs because SNSs represent strategic importance for tourism competitiveness (Leung et al., 2013). Moreover, SNSs can lower costs increase operational efficiency and improve service quality and customer experience (Law et al., 2009).

\section{ACKNOWLEDGEMENTS}

This review study is supported by Excelence and IGU Projects 2016, Faculty of Informatics and Management, University of Hradec Kralove, Czech Republic.

\section{REFERENCES}

Ali, A. and A.J. Frew, 2013. Information and Communication Technologies for Sustainable Tourism. Routledge, Abingdon, England,.

Anonymous, 2013. The five best social networking sites for travel. World Luxury Tourism, Chicago Illinois.

Bennett, S., 2012. The impact of social media on travel and tourism. Four Pillars Hotel, UK. http://www.adweek.com/socialtimes/social-mediatravel-hospitality/466163
Boyd, D.M. and N.B. Ellison, 2007. Social network sites: Definition, history and scholarship. J. Comput. Mediated Commun., 13: 210-230.

Buted, D.R., N.S. Gillespie, J.B. Conti, B.A. Delgado and R.M.P. Marasigan et al., 2014. Effects of social media in the tourism industry of batangas province. Asia Pac. J. Multidiscip. Res., 2: 123-131.

Cox, C., S. Burgess, C. Sellitto and J. Buultjens, 2007. Consumer-Generated Web-Based Tourism Marketing. Sustainable Tourism CRC, Queensland, Australia, ISBN:9781921521591, Pages: 59.

Hootsuite, 2016. Richer social listening: Smarter business decisions. Hootsuite, Vancouver, British Columbia, Canada. https://hootsuite.com/products/insights

Karnstedt, M., M. Rowe, J. Chan, H. Alani and C. Hayes, 2011. The effect of user features on churn in social networks. Proceedings of the 3rd International Conference on Web Science, June 15-17, 2011, ACM, Koblenz, Germany, ISBN:978-1-4503-0855-7, pp: 1-8.

Kiralova, A. and A. Pavliceka, 2015. Development of social media strategies in tourism destination. Procedia Soc. Behav. Sci., 175: 358-366.

Lange, F.W. and S. Elliot, 2012. Understanding the role of social media in destination marketing. Tourismos Int. Multi. J. Tourism, 7: 193-211.

Law, R., R. Leung and D. Buhalis, 2009. Information technology applications in hospitality and tourism: A review of publications from 2005 to 2007. J. Travel Tourism Marketing, 26: 599-623.

Leung, D., R. Law, V.H. Hoof and D. Buhalis, 2013. Social media in tourism and hospitality: A literature review. J. Travel and Tourism Marketing, 30: 3-22.

Morrison, A.M., 2013. Marketing and Managing Tourism Destinations. Routledge, England, UK., ISBN:978-0415-67249-8, Pages: 597.

Nielsen, 2013. The paid social media advertising report. Nielsen Holdings, New York, USA.

PRC., 2016. Social networking fact sheet. Pew Research Center, Washington, D.C., USA. http://www. pewinternet. org/fact-sheet/social-media/

Poulova, P. and B. Klimova, 2015. Social Networks and their Potential for Education. In: Computational Collective Intelligence, Manuel, N., T.N. Ngoc, C. David and T. Bogdan (Eds.). Springer, Switzerland, Europe, ISBN:978-3-319-24305-4, pp: 365-374.

Rathonyi, G., 2013. Influence of social media on tourism: Especially among students of the university of debrecen. Appl. Stud. Agribus. Commer., 10: 105-112.

SD., 2016. Social network sites in travel and tourism. Elsevier, Amsterdam, Netherlands.

SS., 2016. Powerful social media software. Sprout Social, Dearborn, Michigan. http://sproutsocial.com/ 
TA., 2016. Shop here for the lowest hotel prices. TripAdvisor, Needham, Massachusetts. https://www.tripadvisor.com/

Tourism, B., 2016. Online marketing. Small Business Development Corporation, Australia, Oceania. https://www.smallbusiness.wa.gov.au/TourismBoo st/marketing-tips-and-tricks/social-media/
UMOSM., 2008. Power to the people social media tracker. Universal McCann Advertising Agency Company, New York, USA. https://www.scribd.c om/document/3836535/Universal-Mccann-on-SocialMedia\#scribd

Werthner, H. and F. Ricci, 2004. E-commerce and tourism. Commun. ACM, 47: 101-105. 